\title{
Understanding Health Priorities, Behaviors, and Service Utilization Among Brazilian Immigrant Women: Implications for Designing Community-Based Interventions
}

\author{
Leticia Priebe Rocha ${ }^{1}$ - Cristiane Soares ${ }^{2}$ - Alecia McGregor ${ }^{3} \cdot$ Stacy Chen ${ }^{3} \cdot$ Amy Kaplan $^{3} \cdot$ Rebecca R. Rose $^{3}$. \\ Heloisa Galvão ${ }^{4} \cdot$ C. Eduardo Siqueira ${ }^{5} \cdot J_{\text {Jennifer D. Allen }}^{3}$ (D)
}

Received: 3 June 2020 / Revised: 25 November 2020 / Accepted: 26 November 2020 / Published online: 5 January 2021

(C) W. Montague Cobb-NMA Health Institute 2021

\begin{abstract}
Brazilians represent a growing proportion of immigrants in the USA. Little is known about their health or healthcare utilization after their arrival. This study aimed to gather formative data to understand the needs of Brazilian immigrant women to guide public health interventions. We conducted five focus groups with Brazilian women born in Brazil $(n=47)$ and 13 key informant interviews with representatives from Brazilian-serving organizations. Participants were recruited from churches and social service organizations in the Greater Boston area. Findings revealed that mental health was the most pressing health priority; many attributed high levels of anxiety and depression to worries about undocumented status, separation from social networks, and strenuous work schedules. Occupational health issues were frequently mentioned, including musculoskeletal complaints, skin rashes, and respiratory problems. Domestic violence was also a concern, and many women feared reporting to police due to undocumented status. Most reported good access to medical care and described the quality of healthcare services as superior to that available in Brazil. However, many reported challenges with interpersonal communication with providers, dissatisfaction with a perceived unwillingness from providers to order medical tests or prescribe treatment, and limited access to mental health services. There was agreement that effective intervention strategies should use social media, radio, and group education in churches.
\end{abstract}

Keywords Brazilian · Immigrants - Qualitative research · Community-based participatory research · Community-based interventions

\section{Introduction}

According to the US Census, there are an estimated 483,898 Brazilian immigrants living in the USA, although estimates may be inaccurate, since many Brazilians enter the country without documents or overstay their visas [1]. The Brazilian Consulate in Boston estimates 350,000 total Brazilians reside

Jennifer D. Allen

Jennifer.allen@tufts.edu

Leticia Priebe Rocha

Leticia.Rocha@tufts.edu

Cristiane Soares

Cristiane.Soares@tufts.edu

Heloisa Galvão

Helogalvao@aol.com

C. Eduardo Siqueira

Carlos.Siqueira@umb.edu in their jurisdiction of Massachusetts, Vermont, Maine, and New Hampshire, compared with an official estimate from the city of Boston of 90,900 documented immigrants for the same region [1, 2]. Additionally, the Brazilian Foreign Ministry estimates 300,000 Brazilians residing in Miami alone [3]. Among these raw estimates, it is widely held that about $70 \%$ of Brazilians residing in the USA are undocumented [1].

1 Department of Psychology, Tufts University, 490 Boston Ave, Medford, MA 02155, USA

2 Department of Romance Studies, Tufts University, 180 Packard Avenue, Medford, MA 02155, USA

3 Department of Community Health, Tufts University, 574 Boston Avenue, Medford, MA 02155, USA

4 Brazilian Women's Group, 697 Cambridge Street, Brighton, MA 02135, USA

5 School for the Environment, University of Massachusetts Boston, 100 Morrissey Blvd., Boston, MA 02125, USA 
Regardless, it is clear that the number of Brazilians immigrating to the USA is increasing due to economic and political turmoil in Brazil [1]. While the first waves of immigration in the 1980s largely included single young men and women seeking work in the USA and planning to return to Brazil, more recent waves of immigration include women and families who plan to remain in the country [4].

Despite the growth of the Brazilian population in the USA, data on their health status are virtually absent. One challenge with understanding health issues among Brazilian immigrants is that they are categorized as Hispanic or Latino in national surveys. However, most Brazilians do not identify as Latino, and even fewer identify as Hispanic [5]. While this can be most clearly attributed to the language difference between Brazilians and other Latinos, perceived associations between Latino identity and discrimination may influence this as well [4]. Given that Brazilians speak Portuguese, and have distinct cultural influences as a former Portuguese colony with strong ties to African and Indigenous cultures, the differences in selfidentification may be indicative of significant differences in cultural norms and experiences $[1,6]$. As a result, little information is available to understand health needs, priorities and concerns among this population.

As a whole, Brazilians are potentially at risk for health disparities given low levels of English language proficiency $(33 \%)$, education $(40 \% \leq$ high school), insurance coverage ( $21 \%$ uninsured), and higher levels of unemployment (6\%) compared with US counterparts [7]. They also comprise a substantial share of service workers and domestic workers in the metropolitan areas [1]. These circumstances mean that Brazilian women may face additional occupational, interpersonal, and environmental stressors. The gender-specific health impacts that Brazilian women face warrant greater analysis.

There is a paucity of research on the Brazilian immigrant community. We identified less than 15 studies from the last 20 years addressing the health experiences of Brazilian immigrants. Prior studies among Brazilian women have explored a limited number of health issues, including ergonomic, chemical, and biological occupational health and safety issues [8]; the impact of parenting practices on the physical activity and health of children [9]; and increased rates of obesity and chronic disease relating to dietary practices. Taken together, studies find that Brazilian immigrants in the USA experience significant health disparities attributable to a wide variety of social and economic exposures.

The purpose of this qualitative study was to generate a better understanding of health priorities and healthcare utilization among Brazilian women immigrants living in the Greater Boston, MA area. Our intent was to gather formative data to guide the development of future interventions to address identified needs. This study was conducted in partnership with an interdisciplinary team of investigators at Tufts University and the University of Massachusetts Boston,
Brazilian Women's Group (www.brazilianwomensgroup. org), and local City officials.

\section{Methods}

We employed qualitative methods, including focus groups and key informant interviews. For focus groups, we developed a semi-structured focus group interview guide comprised of open-ended questions to assess the following: priority health concerns, factors impacting physical and mental health, barriers to access and receipt of healthcare services, and cultural and linguistic factors that should be considered in future interventions (see Table 1). Those eligible for focus groups were women over the age of 18 who reported being born in Brazil and spoke either Portuguese or English. We recruited a convenience sample by distributing fliers in churches, sending emails through social service agencies, and by word-ofmouth. Prior to participation, women were verbally screened for eligibility and written informed consent was obtained.

Focus groups were conducted in Portuguese by bicultural, native Portuguese-speaking female research team members (LPR, CS) and digitally recorded. Participants completed paper surveys in their preferred language at the end of focus groups that assessed age, country of origin, length of time in the USA, marital status, education, and self-ascribed race/ethnicity. We provided a financial incentive (\$50 U.S.) to compensate participants for their time $(2 \mathrm{~h})$ and potential costs incurred. Data collection took place between September and November 2019.

Key informants are those who can provide unique insights into the health needs of a community by nature of their formal or informal roles. Our objectives for key informant interviews were to assess perceived community health priorities; sociocultural and community-level factors that affect health and healthcare utilization; perceived adequacy of available resources for health; and opinions about effective channels and strategies for public health interventions. The semistructured interview guide was developed based on our prior work $[6,10,11]$ and existing studies of the health of Brazilians in the USA [12-16]. We identified community leaders representing a broad range of sectors (e.g., healthcare, social services, churches) with our community partners and thereafter, through snowball sampling [17]. We aimed to conduct at least 10 interviews and to stop at the point of saturation, when no major new themes emerged from the data.

Key informants were contacted through email and provided with informed consent information. Those who agreed to be interviewed provided written informed consent. Interviews took approximately $30-45 \mathrm{~min}$ and were conducted by members of the research team. Most but not all interviews were audio-taped; in some cases, technical difficulties with recording devices precluded audio recordings. In these cases, 
Table 1 Constructs and questions for focus groups and key informant interviews

\begin{tabular}{|c|c|c|}
\hline Construct & Sample focus group questions & Sample key informant question \\
\hline Health priorities & $\begin{array}{l}\text {-What do you think are the most important health } \\
\text { problems of Brazilian women in your community? } \\
\text { - What resources are available for these issues in your } \\
\text { community? } \\
\text { - What resources do you think are most needed? }\end{array}$ & $\begin{array}{l}\text { - What do you perceive are the greatest healthcare } \\
\text { priorities for Brazilian women? } \\
\text { - What do you perceive are some of the most } \\
\text { requested or sought-after health services? }\end{array}$ \\
\hline $\begin{array}{l}\text { Preventative health } \\
\text { behaviors }\end{array}$ & $\begin{array}{l}\text { - What are some things you do to take care of your } \\
\text { health? } \\
\text { - What keeps you from practicing healthy behaviors? }\end{array}$ & $\begin{array}{l}\text { - To the best of your knowledge, what do Brazilian } \\
\text { women do to protect and promote their health? } \\
\text { - Which behaviors do they prioritize? }\end{array}$ \\
\hline $\begin{array}{l}\text { Healthcare usage, } \\
\text { perceptions, \& } \\
\text { barriers }\end{array}$ & $\begin{array}{l}\text { - Where do people in your community get health care } \\
\text { services? } \\
\text { - Can people in your community get the care they } \\
\text { need? Why or why not? } \\
\text { - In general, do you think your community receives } \\
\text { high-quality health care? }\end{array}$ & $\begin{array}{l}\text { - To the best of your knowledge, where do Brazilian } \\
\text { women seek and receive healthcare? } \\
\text { - What health services are accessible and what do you think is needed? } \\
\text { - How do you think Brazilian women perceive the care that they } \\
\text { receive? }\end{array}$ \\
\hline Intervention planning & $\begin{array}{l}\text { - What are kinds of programs have been successful in } \\
\text { your community? What made them successful? } \\
\text { - What are some health initiatives that have not been } \\
\text { useful? Why? } \\
\text { - What are some of the most effective means of } \\
\text { communicating within your community? }\end{array}$ & $\begin{array}{l}\text {-What kinds of programs do you believe have been successful in the } \\
\text { Brazilian immigrant community? What made them successful? } \\
\text { - What are some health initiatives that have not been useful? Why? }\end{array}$ \\
\hline Occupational health & None & $\begin{array}{l}\text {-What are the most common health } \\
\text { complaints/problems related to work settings? } \\
\text { - What do you know about preventative or safety } \\
\text { measures used in these industries? } \\
\text { - Do workers receive health and safety training? }\end{array}$ \\
\hline
\end{tabular}

interviewers took extensive notes by hand and summarized findings immediately following the interview. Data collection took place between June and November 2019. All study procedures were approved by the Social, Behavioral, and Educational Research Institutional Review Board at Tufts University.

\section{Analysis}

Focus groups were audio-recorded and transcribed verbatim, first in Portuguese and then translated to English by a certified translator. Portuguese and English language transcripts were reviewed by two native Brazilian team members for accuracy of linguistic and cultural interpretation. We used a deductive approach to coding and analysis of focus group data [17-19]. Members of the team independently reviewed all transcripts to identify major themes and propose higher-order coding schemes. We met as a team to refine codes for major and subordinate themes through an iterative process. When divergent interpretations occurred, we reviewed and discussed original transcripts (in both Portuguese and English) until we reached consensus. Major and subordinate themes were then organized using hierarchical database indexing software (Atlas@) $[19,20]$. Descriptive statistics (frequencies, percentages) were calculated to describe the socio-demographic characteristics of participants gathered through paper surveys.
For key informant interviews, two team members independently reviewed available audio tapes and hand-written notes and summaries generated by interviewers immediately following interviews. Each team member independently identified initial themes and, in subsequent team meetings, discussed interpretations and came to consensus about dominant themes, using direct quotes to support our analysis [19].

\section{Results}

\section{Characteristics of Participants (Table 2)}

Focus group participants $(n=47)$ spanned in age from 22 to 74 years $($ mean $=47.04)$. All participants were born in Brazil, except for one woman born in Portugal who emigrated to Brazil at an early age. The range of time spent living in the USA varied between 6 months and 33 years $($ mean $=14.76)$, although most (70.1\%) reported having lived in the USA for more than 10 years. In the first focus group, participants were asked to identify their race from a pre-set list of options based on those presented in the US Census. However, participants expressed difficulty responding to the fixed-choice question on race/ethnicity; the majority of women felt that the response categories were not reflective of their identity. In the next focus group, we allowed a free-text write-in response. In the remaining focus groups, participants were not asked to 
Table 2 Socio-demographic characteristics of focus group participants $(n=47)$

\begin{tabular}{|c|c|c|}
\hline & $N$ & $(\%)$ \\
\hline \multicolumn{3}{|l|}{ Age (years) mean } \\
\hline $35-44$ & 11 & 23.4 \\
\hline $45-54$ & 16 & 34.1 \\
\hline $55-64$ & 6 & 12.7 \\
\hline $65-70$ & 3 & 6.3 \\
\hline $71+$ & 3 & 6.4 \\
\hline Missing & 0 & 0 \\
\hline \multicolumn{3}{|l|}{ Race/ethnicity } \\
\hline Brazilian & 2 & 4.3 \\
\hline Brown & 3 & 6.4 \\
\hline Dark & 1 & 2.1 \\
\hline Mixed race & 1 & 2.1 \\
\hline South American & 1 & 2.1 \\
\hline White & 8 & 17.0 \\
\hline White/European & 1 & 2.1 \\
\hline Missing & 30 & 63.8 \\
\hline \multicolumn{3}{|l|}{ Latino/Hispanic } \\
\hline Yes & 40 & 85.1 \\
\hline No & 7 & 12.8 \\
\hline Missing & 1 & 2.1 \\
\hline \multicolumn{3}{|l|}{ Marital status } \\
\hline Single & 4 & 8.5 \\
\hline Living as married & 1 & 2.1 \\
\hline Married & 33 & 70.2 \\
\hline Widowed & 3 & 6.4 \\
\hline Divorced & 6 & 12.8 \\
\hline Missing & 0 & 0 \\
\hline \multicolumn{3}{|l|}{ Educational level } \\
\hline Primary school & 10 & 21.3 \\
\hline High school or GED & 13 & 27.7 \\
\hline Vocational school & 8 & 17.0 \\
\hline 2 years college (associate degree) & 4 & 8.5 \\
\hline 4 years college (bachelor's degree) & 5 & 10.6 \\
\hline More than 4 years of college & 6 & 12.8 \\
\hline Missing & 1 & 2.1 \\
\hline \multicolumn{3}{|l|}{ Nativity } \\
\hline Brazil & 46 & 97.9 \\
\hline USA & 0 & 0 \\
\hline Other & 1 & 2.1 \\
\hline Missing & 0 & 0 \\
\hline \multicolumn{3}{|l|}{ Time living in the USA (mean in years) } \\
\hline$<1$ year & 2 & 4.2 \\
\hline $1-4$ years & 5 & 10.5 \\
\hline $5-9$ years & 4 & 8.5 \\
\hline $10-14$ years & 11 & 23.4 \\
\hline 15-19 years & 10 & 21.4 \\
\hline 20-24 years & 6 & 12.7 \\
\hline 25-29 years & 2 & 4.2 \\
\hline $30+$ & 4 & 8.4 \\
\hline Missing & 3 & 6.4 \\
\hline
\end{tabular}

* Total varies due to missing responses; percentages may not total $100 \%$ due to rounding

identify their race in any form as initial participants described the question as culturally irrelevant and off-putting. Out of the 47 participants, only 17 women from the first two focus groups were presented with the question. We note this as a limitation in the "Discussion" section. Among the total 17 responses, 9 participants described themselves as white, 2 as Brazilian, 3 as Brown, 1 as dark, 1 as mixed race, and 1 as
South American. Approximately, two-thirds (65.7\%) reported having a high school degree or less and the majority $(71.8 \%)$ were married or living with a partner.

We conducted 13 key informant interviews, 3 of which involved 2 participants in the same interview. Key informants were healthcare providers $(n=6)$, hospital administrators $(n=$ $2)$, social service workers $(n=7)$, and pastors $(n=1)$. Most interviewees were female (88\%) and the majority of interviews were conducted in English (62\%). Five of the 13 interviews were not audio-recorded due to technical failure of recording devices.

\section{Major Themes}

Due to extensive overlap in themes raised in both focus groups and key informant interviews, we present combined results as the juxtaposition of findings better enables a contextualized understanding of themes. Results are reported in the sequence in which topics were discussed (see Table 1 for sample questions and Table 3 for additional quotes).

\section{Mental Health}

Across all interviews, mental health issues, including high levels of stress, anxiety, and depression, were cited as the most pressing health concerns. Participants reported that anxiety and depression are very common among women and have been on the rise in recent years. For example, women in focus groups made statements such as follows: "The biggest issue nowadays is depression." Many attributed poor mental health to immigration status and fears of deportation. A key informant explained "Depression, anxiety, PTSD-much of this is related to immigration stressors, fear of deportation, family separation, and difficulties with adapting to life in the U.S." Another common perception was that depression and anxiety were related to separation from friends and family in Brazil and feelings of social isolation in the USA. Another key informant explained "In the Brazilian community... you see a lot of family separation... you see a lot of depression and anxiety ... or panic disorders that they never had in Brazil and start manifesting only in the U.S."

\section{Occupational Health and Safety}

Another major theme across all interviews was occupational health concerns, which were particularly prevalent among domestic workers. Participants cited that fatigue, musculoskeletal injuries, and hazardous exposures were common. Women talked about coming to the USA explicitly for the purpose of making money, stating things such as "Most of us Brazilians, we came here just to work." Working long hours in physically 
Table 3 Major themes and supporting quotes

\begin{tabular}{|c|c|c|}
\hline Theme & Supporting quotes from key informants & Supporting quotes from focus groups \\
\hline Mental health & $\begin{array}{l}\text { "There is definitely a huge concern involving mental health. A lot } \\
\text { of women, they experience symptoms of depression..." }\end{array}$ & $\begin{array}{l}\text { "I think women suffer much more from anxiety and } \\
\text { depression here. We're very lonely, we have no family." } \\
\text { "I think one of the things ....is the matter of the anxiety due } \\
\text { to the lack of documentation, immigration status." }\end{array}$ \\
\hline Occupational health & $\begin{array}{l}\text { "When we talk about the occupational hazards, it's simply hard } \\
\text { work, it takes a hard toll on your body... You have their perfect } \\
\text { equation for getting hurt, getting hurt quick." }\end{array}$ & $\begin{array}{l}\text { "You learn how to work, do not use strong stuff... It's } \\
\text { practical but if person does not know [about } \\
\text { protections], they do it wrong and then all these [health } \\
\text { problems] happen." }\end{array}$ \\
\hline Domestic violence & $\begin{array}{l}\text { "Asking for help, it is difficult for anyone in a domestic violence } \\
\text { situation, but immigrant women face even more barriers and } \\
\text { fears in reporting." }\end{array}$ & $\begin{array}{l}\text { "For years I suffered domestic violence...afraid of asking } \\
\text { for help because I was going to be deported." }\end{array}$ \\
\hline $\begin{array}{l}\text { Healthcare access and } \\
\text { utilization }\end{array}$ & $\begin{array}{l}\text { "Good quality of care' is where there is thorough examination } \\
\text { even if the symptoms or lack of symptoms do not warrant } \\
\text { multiple tests..." }\end{array}$ & $\begin{array}{l}\text { "[My doctor] could have referred me to a psychologist, but } \\
\text { he did not. I picked up a psychologist in Brazil and did it } \\
\text { via Facetime. And that's what solved my problem. But } \\
\text { it wasn't a doctor who referred me to therapy." } \\
\text { "How can I be comfortable talking about my health when } \\
\text { the doctor goes 'Hurry up. Hurry up!"” }\end{array}$ \\
\hline $\begin{array}{l}\text { Preventative healthcare } \\
\text { and behaviors }\end{array}$ & $\begin{array}{l}\text { "Women in the Brazilian community work to an extent where } \\
\text { they cannot take care of their health. It is not a priority. } \\
\text { Everyone else in the family, and almost everything else in their } \\
\text { lives, comes first." }\end{array}$ & $\begin{array}{l}\text { "I get home so tired [after work] that I do not want to eat. I } \\
\text { just want to lie down." }\end{array}$ \\
\hline $\begin{array}{l}\text { Faith and importance of } \\
\text { church }\end{array}$ & $\begin{array}{l}\text { "Faith is key in the Brazilian population. It is sometimes the only } \\
\text { way to build networks for people. It is in the center of their } \\
\text { lives, beyond just spirituality, it is a social thing." }\end{array}$ & $\begin{array}{l}\text { "In a church, the spiritual part helps a lot... This is very } \\
\text { important." }\end{array}$ \\
\hline $\begin{array}{l}\text { Community strengths } \\
\text { and assets }\end{array}$ & $\begin{array}{l}\text { "Brazilians are very social and warm, which is a protective } \\
\text { factor." }\end{array}$ & $\begin{array}{l}\text { "We are connected in many ways. Word of mouth works } \\
\text { so well because of these connections. We are a social } \\
\text { people, full of life and warmth." }\end{array}$ \\
\hline $\begin{array}{l}\text { Recommendations for } \\
\text { community-based } \\
\text { interventions }\end{array}$ & $\begin{array}{l}\text { "We have lots of Facebook pages in Portuguese like Negócio } \\
\text { Fechado (Done Deal), and they [Brazilian women] really } \\
\text { interact with those channels." } \\
\text { "Radio is a very important media for immigrants. So, if we had } 10 \\
\text { minutes or so every week...of trusted information that the } \\
\text { broadcasters could divulge, it would be very good. " }\end{array}$ & $\begin{array}{l}\text { "In a church I used to go, they had really good programs, } \\
\text { they offered mammograms and other screenings, but the } \\
\text { ones around here I do not see that." }\end{array}$ \\
\hline
\end{tabular}

demanding jobs was common. Focus group participants reported "...people who work with cleaning, clean three, four, five, six houses... it's a fatigue that cannot be explained. You're alive, but ... you don't know how." Many focus group participants, especially those who said that they cleaned houses, reported having musculoskeletal injuries, describing physical pain in joints, backs, and hands. Others added:

Many women, perhaps because they are not legal [immigrants], need to go house-cleaning... I see many people who have... back injury, sciatic nerve problems, pelvic, pain in the shoulders and legs...

Participants also reported that asthma, allergies, and skin rashes were common, and these issues were most often attributed to exposure to potentially harmful cleaning products used in domestic work. A key informant reinforced this, stating "The issue of repetitive work that causes pain, respiratory issues or even skin allergies because of the products used in the workplace."

\section{Domestic Violence}

In 3 of the 5 focus groups and in 8 of the 13 key informant interviews, domestic violence was discussed. Several key informants thought that the prevalence of domestic violence was higher in the USA than in Brazil due to changes in traditional gender roles post-immigration (e.g., the female partner works and becomes financially independent). One key informant theorized:

One thing I see a lot is how the families are structured. How even if the woman is the main breadwinner, the man is still head of household. Gender constructions are very strong. A lot of families, the woman knows what her role is within that family.

Both key informants and focus group participants emphasized that women were reluctant to report violence because of fears of deportation or retaliation: 
... there is a lot of fear about getting help. Even for those women where their abuser is also undocumented. [The abuser] threatens that if they get deported, they will kill her family in Brazil. Women feel trapped.

\section{Healthcare Access and Utilization}

There were two major themes that emerged with regard to access to healthcare. First, there was general consensus that most women had good access to medical care through public programs or private insurance. Many focus group participants expressed that they were able to obtain care, even if they did not have insurance or the ability to pay. One key informant noted the following: "People are generally happy with their doctors, the care they receive...once they are treated or seen by doctors, the women are happy."

In contrast, there was a great deal of discussion about lack of access to mental healthcare, particularly those who speak Portuguese or understand Brazilian culture. One of the key informants, a Portuguese-speaking psychologist, noted:

The language makes all the difference - my new clients tell me all the time that I am the only therapist they could find that spoke their language and understands the culture.

Virtually, all women in focus groups concurred that healthcare in the USA is superior to care they had received in Brazil. Participants made statements such as "[Healthcare is] a ten out of ten." Key informants had similar perceptions: "People are happy with their care. They are grateful for the services they are able to get, especially when compared to Brazil."

While most voiced their satisfaction with healthcare in the USA, they also discussed cultural differences in expectations of the patient/provider relationship. For example, many expressed frustration or dissatisfaction with a perceived a lack of physician initiative in performing comprehensive diagnostic testing. Focus group participants reported that US doctors are reticent about doing physical exams and ordering medical tests, which they perceived resulted in delayed diagnosis of problems. For example, one woman explained:

We have different mindsets. In Brazil, the doctor says you need it [exam or test] and you're done. Here, sometimes you must ask the doctor, "I want the examinations." I understand that it is cultural, but all over the world, they learn to do a complete physical examination, from head to toe.

Additionally, women in focus groups spoke about providers' lack of interpersonal connectedness with patients. This was largely attributed to a lack of time during clinical encounters: ...the perception [of care] is not negative. People still go to their doctors. What they miss the most is their personal interactions, so they feel comfortable sharing all of their symptoms and problems. The issues with seeking care are primarily around language and with the doctors having less time and interactions that are different from Brazil, which makes patients uncomfortable at times. Then people think 'I'm not going to go there anymore' or abandon the whole thing altogether until they get really sick.

\section{Preventive Healthcare and Health Behaviors}

Many focus group participants reported that they did not go to healthcare providers for preventive health visits. A key informant explained that "Preventative care is not common [in Brazil]. You go to the doctor when you have to." Work was frequently cited as a barrier to getting healthcare, with one focus group participant stating the following: "If I have a medical appointment? [I won't go if] I'll have to miss a day of work." Work was also perceived as a barrier to engaging in healthy behaviors, particularly good eating habits. A key informant highlighted this theme:

How can women take care of their body when they work 10-14-hour days and have to take care of their families and the house? They are not going to prioritize healthy nutrition or exercise. They just won't - they can't.

\section{Faith and the Importance of Church}

The role of faith and the church were repeatedly emphasized. Focus group participants made statements about their belief that all things, including health, come from God. For example, women made statements such as the following: “...I'm in good hands, with good doctors, with God ahead of everything ..." Across all interviews, participants spoke of the importance of the church as a source of social support and connection. A key informant reported that "... the church and the faith community... is paramount... A lot of people are away from their families... The faith community can fill that gap."

\section{Community Strengths and Assets}

We also identified a number of important community strengths and assets. Throughout focus groups, women described tight knit family structures and interpersonal warmth and connectedness among Brazilians. Several participants perceived that these characteristics result in strong and efficient communication networks within the community. One key informant noted that "All you need is one Brazilian to hear about a program or event and the news will spread so 
much. It's word of mouth, social media... then those networks are strong and word spreads like fire."

Key informants also acknowledged the culturally embedded willingness to seek information and assistance when necessary as an asset. One participant highlighted:

Brazilians do go after help and make use of the resources available to them. It's cultural. This doesn't always mean adherence to treatment... but it does mean seeking out information and using it.

\section{Recommendations for Community-Based Interventions}

In all interviews, faith-based organizations were cited as potentially effective venues for implementing health interventions. A few focus group participants recalled that programs based in churches were well-received, although most reported that their own churches did not offer any such program. The overarching rationale for providing programs in faith-based was that Brazilians spend a lot of time in church, church is a key source of social support and networks, and that faith in God is important for physical and mental health. One woman described the following: "When the person is needy, most of them go to church to hear a word of comfort that can cheer them up.... Even those who don't believe seek to come and listen."

Social media was consistently reported as a highly effective means of reaching Brazilians, particularly because people are geographically separated, work long hours, and are already using platforms such as Facebook and WhatsApp. Another frequently cited channel for communication was Brazilian radio, although some observed that many women worked in settings where it was not feasible to listen to radio programs.

\section{Discussion}

Our results suggest that mental health, occupational health and safety, and domestic violence are major health concerns among Brazilian women. While most felt that there was adequate access to medical care, there was a perceived lack of mental health providers who speak Portuguese or understood Brazilian culture.

Mental health needs have been previously documented in the Brazilian immigrant community. A 2009 communitybased study conducted in Massachusetts found that $51 \%$ of Brazilian immigrants self-endorsed depression and $44 \%$ endorsed anxiety [21]. A more recent study of Brazilian immigrants recruited through churches and the Consulate General of Brazil in Boston $(n=401)$ found that more than a third $(35 \%)$ had depressive symptomatology [22]. The high reported prevalence of mental health needs among Brazilian women makes sense in the current political environment, as more punitive immigration policies are adopted [23]. Previous studies in the USA found an association between more restrictive state-level immigration policies and higher mental health morbidity among Latinos [24].

Our findings regarding occupational health and safety concerns are also consistent with prior studies of Brazilian immigrants. Taken together, these studies found that Brazilian immigrants often come to the USA to improve their socioeconomic status, working as many hours as possible often in low-paying, physically demanding jobs [4, 15]. Housecleaners, in particular, are often exposed to chemical and biological hazards, as those are often not monitored or regulated in domestic settings [15]. Women in these jobs are also at risk for back injuries and joint pain due to repetitive tasks [25]. Additionally, immigrant workers may be exploited on the job due to language barriers, non-transferability of professional skills, undocumented status, and discrimination [26]. A cross-sectional study of predominantly Brazilian women workers found that many reported difficulty negotiating contracts due to language barriers and social vulnerability, particularly among those with undocumented status [15]. Available data shows that nearly a third of Brazilian women work in domestic settings at least once during their residence in the USA [27], so these issues warrant additional attention.

To our knowledge, domestic violence is a concern that has not been previously documented among Brazilian immigrants, although fear of reporting crimes to police due to immigration fears has been found in numerous studies among other foreign-born groups [28]. While the literature regarding intimate partner violence experienced by Brazilian immigrants is sparse, the prevalence of lifetime intimate partner violence for Latina immigrants in the USA has been estimated at $22 \%$ for physical assault and $73 \%$ for psychological aggression $[29,30]$. According to the WHO Multi-Country Study on Women's Health and Domestic Violence against women, the proportion of Brazilian women age 16+ who experienced intimate partner violence (physical or sexual) at least once in their lifetime is $16.5 \%$ [31, 32]. Alterations in gender roles, which commonly occur when immigrating from a highly patriarchal society, shift power dynamics and may be a contributing factor to higher rates of domestic violence [33].

The finding that Brazilian women had adequate access to medical care and were generally satisfied with the US healthcare system has been previously reported among those residing in Massachusetts $[12,13]$. This may be due to healthcare reform passed in Massachusetts in 2006 which mandated free or subsidized healthcare insurance for residents earning less than $150 \%$ and $300 \%$ of federal poverty level. As a result, residents of Massachusetts have greater access to healthcare compared with other states [34]. Additionally, our findings may be at least partially attributed to the fact that 
convenience sampling was employed to identify focus group participants through methods such as word-of-mouth, which may lead to under-representation of the most isolated members of the community. Despite having good access to medical care, there was a perception that providers fail to connect with or get to know their patients. Women also spoke about their disappointment with the short duration of appointments and perceived reluctance of their clinicians to order tests or prescribe treatment. Our finding about cultural differences in patient/provider communication and expectations regarding the outcome of health visits among Brazilians has also been reported elsewhere [12, 35]. However, it is important to note that while women reported having good access to medical care, there was a perceived gap in mental health services, particularly due to the limited numbers of Portuguesespeaking mental health providers.

The importance of religion and the church among Brazilian immigrant women is not surprising. Church communities not only offer spiritual support but also the opportunity to connect with others from similar language and ethnic groups. Numerous studies document that immigrant populations often find church and religion to be major sources of consolation, connection, and social support [36]. There is also empirical evidence that social networks in churches can be leveraged to support health programs [37-39]. However, we acknowledge that the importance of church may be overestimated, given that some of the focus groups were conducted in church settings.

Before discussing implications of the study, we acknowledge limitations. Qualitative studies such as ours involve small purposive samples and are not intended to generate generalizable findings. Key informants were identified in part by snowball sampling, which can lead to self-selection bias and/ or overrepresentation among individuals within the same social networks. Use of snowball sampling for key informants and convenience sampling for focus group participants may result in exclusion of individuals who are socially isolated and who lack connections to resources within their community. As a result, our findings may not fully reflect the healthcare experiences of those community members. These findings may also be subject to social desirability bias, or the tendency of respondents to answer questions in a manner that would be viewed favorably by others. Additionally, as noted above, the fact that some focus groups took place in churches likely overestimates the importance of faith and the potential for conducting interventions in churches. The fact that we do not have data on racial categorization of women in the sample may be seen as a limitation. However, it is also a finding reflecting that the standard categories in the US census may not be capturing accurate data for Brazilians.

Nevertheless, the goal of this exploratory study was not to achieve a representative sample or to test hypotheses. Rather, our goal was to identify a range of relevant issues and obtain the depth and detail of understanding that qualitative research can provide. A strength is the inclusion of key informant interviews with focus group discussions, which enabled us to assess juxtaposition of findings from the two data sources and triangulate findings. The fact that there was extensive overlap in themes raised by both groups provides some reassurance that the study findings are valid. We have presented our preliminary findings to community members ("member checking") [40], and these activities have also reassured us that findings are meaningful for community members.

\section{Implications for Practice}

Notwithstanding limitations, our study adds to the limited research on the health of Brazilian immigrant women and can inform efforts to design culturally relevant health interventions for this population. Given recurring concerns about mental health, our results highlight the need for accessible mental health services. One prior study documented that mental health services delivered by linguistically- and culturallycompetent providers led to higher retention in care for Brazilian immigrant patients compared to those treated in "usual care" settings [41]. Systematic reviews of interventions to improve providers' abilities to provide culturally competent care (e.g., observation with direct feedback) have been found to improve patient satisfaction with care, although more research is needed [42]. Our finding that women perceived that providers fail to connect with them or get to know them has several implications. Providers need to be made aware of the unique needs and "hands-on" approach desired by Brazilian women, perhaps through the development of culturally specific training tools. Additionally, recruiting Brazilians into the fields of psychology and psychiatry will be important so that provider teams that are better equipped to serve the needs of this community.

This and prior studies suggest a need for effective interventions for Brazilian immigrant workers in the domestic and service industries. There are a relatively large number of evidence-based worksite interventions to reduce musculoskeletal injuries, which include ergonomic modifications, strength training, and policy interventions, as well as individual-level protections $[43,44]$. We identified one intervention that promoted the use of environmentally friendly cleaning products among Brazilian immigrant women working as house cleaners [45]. After switching to green products, all participants reported less adverse health outcomes linked to the use of traditional cleaning products [45]. This same intervention had a secondary benefit in that it utilized collaborative decision-making between participants to address locus-ofcontrol issues, experiences of solitude, and difficulty negotiating contracts [45]. These findings suggest that similar interventions may be developed or adapted to address ergonomic and social issues. 
If confirmed in larger studies, our findings also suggest a need for interventions to address domestic violence. Our study participants cited fears about deportation or other immigration-related repercussions if they reported violence to the police, and this is corroborated by studies among other immigrant groups [29, 30]. A systematic review of interventions to address intimate partner violence among Latinas found few evidence-based interventions. Among studies showing a positive intervention effect, common intervention elements included multiple group sessions focused on sexual communication, information about community resources, and peer support [46]. However, it is important to note that interventions that appear to work with one cultural group may not work for others. Of the interventions described in the systematic review [46], none provided information about how interventions were culturally tailored. Research is needed to understand how best to adapt and tailor evidence-based interventions for Brazilians, particularly around changing gender roles post immigration.

We also identified important strengths within the Brazilian community. Some of these include tight-knit family structures, both in the USA and in Brazil. Women also described their relationships with friends and other community members as "close" and "warm." This suggests that interventions that employ community members (e.g., community health workers) may hold promise. Many participants also described the importance of faith and pointed to their churches as a hub of social and emotional support. The potential to build upon existing social connections and support offered by churches is also a strength. Indeed, growing evidence suggests that "faithbased" programs (i.e., rooted in religious teaching) and health interventions with cultural and religious adaptations (e.g., integration of prayer, religious traditions) are effective at reaching immigrant communities [47-49].

This exploratory study also points to areas for future research. Data from a larger, more representative sample of Brazilian women is needed to determine the prevalence of health issues identified here and to identify themes that might have been missed. Understanding the prevalence of mental health issues, occupational health and safety concerns and domestic violence warrant special attention, as they were perceived to be highly prevalent and on the rise among Brazilian women. Additionally, further research is needed to understand how the issues raised in this study have been impacted by the social, economic, and health consequences of the COVID-19 pandemic. While these issues always remain pressing, the increasing mortality and morbidity arising from COVID-19 serve to highlight the urgency of health priorities in the Brazilian community. Information to guide the development and adaptation of effective interventions to address these issues and leverage existing community strengths can facilitate this process.
Acknowledgments We thank all of the research participants for sharing their experiences and valuable insights. We are indebted to Adriana Fernandes who provided consultation on data collection instruments, assisted in recruitment, and participated in data collection.

We are indebted to the women who participated in this research for the many insights and experiences they shared. We are very grateful for key informants and community partners from the Brazilian Women's Group, SomerViva, the Brazilian Consulate, the Somerville Health Department, the Massachusetts Alliance of Portuguese Speakers, the Brazilian Workers Center, the New England Community Center, and Boston Behavioral Medicine.

Availability of Data and Material If requested, data may be shared at the discretion of the principal investigator, with requests considered on a case-by-case basis and with an executed data use agreement in place.

Authors' contributions All authors made substantial contributions to the interpretation of data and have drafted the work or substantively revised it. Specifically, LR and JDA conceptualized and designed the study and drafted the manuscript. LPR, CS, and JDA collected data and conducted data analysis. AM, CS, SC, AK, RR, HG, and CES contributed to manuscript drafts and approved final version.

\section{Compliance with Ethical Standards}

Conflict of Interest The authors declare that they have no conflicts of interest.

Ethics Approval All protocols and procedures were approved by the Social, Behavioral \& Educational Research Institutional Review Board of Tufts University, Medford, MA.

Consent for Participation All research participants provided informed consent.

\section{References}

1. Holmes L, Marcelli E, Buxton O. (In)visible (im)migrants: the health and socioeconomic intergration of Brazilians in Metropolitan Boston. San Diego: Center for Behavioral and Community Health Studies, San Diego State University; 2007.

2. Boston Planning \& Development Agency Research Division. Brazilians in Boston [Internet]. 2017. Available from: http:// www.bostonplans.org/getattachment/ad985146-c34a-4f51-8c6eb277d4cda498. Accessed 7 June 2019.

3. Estados Unidos [Internet]. Available from: http://www. portalconsular.itamaraty.gov.br/seu-destino/estados-unidos\# comunidade-brasileira-e-principais-destinos. Accessed 21 Nov 2020.

4. Joseph TD. "My life was filled with constant anxiety": antiimmigrant discrimination, undocumented status, and their mental health implications for Brazilian immigrants. Race Soc Probl. 2011;3:170-81.

5. Cao B. Becoming Brazuca: Brazilian immigration to the United States. Soc Identities Routledge. 2010;16:711-4.

6. Lima A, Siqueira CE. Brazilians in the U.S. and Massachusetts: a demographic and economic profile [Internet]. Gastón Institute Publications; 2007. Available from: https://scholarworks.umb.edu/ cgi/viewcontent.cgi .article $=1049 \&$ context $=$ gaston_pubs. Accessed 22 July 2019. 
7. Bureau USC. Selected population profile in the United States: 2017 American Community Survey 1-Year Estimates. Fact Finder. Available from: https://factfinder.census.gov/faces/tableservices/ jsf/pages/productview.xhtml?src=bkmk. Accessed 28 June 2019.

8. Panikkar B, Woodin MA, Brugge D, Hyatt R, Gute DM. Characterizing the low wage immigrant workforce: a comparative analysis of the health disparities among selected occupations in Somerville, Massachusetts. Am J Ind Med 2014;57:516-526.

9. Lindsay AC, Arruda CAM, De Andrade GP, Machado MMT, Greaney ML. Parenting practices that may encourage and discourage physical activity in preschool-age children of Brazilian immigrant families: a qualitative study. Turner K, editor. PLOS ONE. 2019;14:e0214143.

10. Allen JD, Leyva B, Hilaire DM, Reich AJ, Martinez LS. Priorities, concerns and unmet needs among Haitians in Boston after the 2010 earthquake. Health Soc Care Community. 2016;24:687-98.

11. Allen JD, Torres MI, Tom LS, Leyva B, Galeas AV, Ospino H. Dissemination of evidence-based cancer control interventions among Catholic faith-based organizations: results from the CRUZA randomized trial. Implement Sci IS. 2016;11:74.

12. de Duarte N, A, Escrivão Junior Á, Siqueira S. Access to health service by brazilian emigrants in the United States. Saúde E Soc. 2013;22:365-76.

13. Lindsay A, de Oliveira MG, Machado M. Brazilian immigrant womens perspectives and experiences of health care in the United States: a qualitative study. Int J Qual Methods. 2016;15.

14. Lindsay AC, de Oliveira MG, Wallington SF, Greaney ML, Machado MMT, Freitag Pagliuca LM, et al. Access and utilization of healthcare services in Massachusetts, United States: a qualitative study of the perspectives and experiences of Brazilian-born immigrant women. BMC Health Serv Res [Internet]. 2016. Available from: https://dash.harvard.edu/handle/1/2940781. Accessed 22 Feb 2019.

15. Siqueira CE, Roche AG. Occupational health profile of Brazilian immigrant housecleaners in Massachusetts. NEW Solut J Environ Occup Health Policy 2013;23:505-520.

16. Tajik M, Galvão HM, Eduardo SC. Health survey instrument development through a community-based participatory research approach: health promoting lifestyle profile (HPLP-II) and Brazilian immigrants in greater Boston. J Immigr Minor Health N Y. 2010;12:390-7.

17. Glaser BG, Strauss AL. The Discovery of grounded theory: strategies for qualitative research. Transaction Publishers; 2009.

18. Fereday J, Muir-Cochrane E. Demonstrating rigor using thematic analysis: a hybrid approach of inductive and deductive coding and theme development. Int J Qual Methods SAGE Publications Inc. 2006;5:80-92.

19. Garner R, Scott GM. Doing qualitative research: designs, methods, and techniques. Pearson Education; 2013.

20. Catterall M, Maclaran P. Focus group data and qualitative analysis programs: coding the moving picture as well as the snapshots. Sociol Res Online SAGE Publications Ltd. 1997;2:41-9.

21. Sánchez M, Cardemil E, Adams ST, Calista JL, Connell J, DePalo A, et al. Brave new world: mental health experiences of Puerto Ricans, immigrant Latinos, and Brazilians in Massachusetts. Cultur Divers Ethnic Minor Psychol. 2014;20:16-26.

22. Lazar-Neto F, Louzada ACS, de Moura RF, Calixto FM, Castro MC. Depression and its correlates among Brazilian immigrants in Massachusetts, USA. J Immigr Minor Health. 2018;20:832-40

23. Hatzenbuehler ML, Prins SJ, Flake M, Philbin M, Frazer MS, Hagen D, et al. Immigration policies and mental health morbidity among Latinos: a state-level analysis. Soc Sci Med. 1982;2017(174):169-78.

24. Venkataramani AS, Shah SJ, O’Brien R, Kawachi I, Tsai AC. Health consequences of the US Deferred Action for Childhood
Arrivals (DACA) immigration programme: a quasi-experimental study. Lancet Public Health. 2017;2:e175-81.

25. Theodore N, Burnham L. Home economics: the invisible and unregulated world of domestic work. 2012.

26. Panikkar B. Migration, work, health, and justice: occupational safety and health among immigrant workers in Somerville, MA [Internet]. Medford: Tufts University; 2011. Available from: https://dl.tufts.edu/pdfviewer/8s45qn022/m613n912g. Accessed 4 June 2019.

27. Tracy N, Sieber T, Moir S. INVISIBLE NO MORE: domestic workers organizing in Massachusetts and beyond. Labor Stud Fac Publ Ser [Internet]. 2014. Available from: https://scholarworks. umb.edu/laborstudies_faculty_pubs/1. Accessed 12 May 2020 .

28. Sabri B, Campbell JC, Messing JT. Intimate Partner Homicides in the United States, 2003-2013: A comparison of immigrants and nonimmigrant victims. J Interpers Violence 2018;886260518792249.

29. Reina A, Lohman B. Barriers preventing Latina immigrants from seeking advocacy services for domestic violence victims: a qualitative analysis. J Fam Violence. 2015(4);30:479-88.

30. Reina AS, Maldonado MM, Lohman BJ. Undocumented Latina networks and responses to domestic violence in a new immigrant gateway: toward a place-specific analysis. Violence Against Women. 2013;19(12):1472-97.

31. Blima L, Ana S, D'oliveirai FPL, França-juniorii I, Prevalence SD, Paula A, et al. Prevalence of intimate partner violence against women in regions of Brazil. 2007.

32. Bott S, Guedes A, Ruiz-Celis AP, Mendoza JA. Intimate partner violence in the Americas: a systematic review and reanalysis of national prevalence estimates. Rev Panam Salud Pública [Internet]. 2019;43. Available from: https://www.ncbi.nlm.nih. gov/pmc/articles/PMC6425989. Accessed 21 May 2020.

33. Debiaggi SDD. Changing gender roles: Brazilian immigrant families in the U.S. New York: LFB Scholarly Publishing LLC; 2001.

34. Gray D, Barton B, Azam I, Bonnett D. 2017 National healthcare quality and disparities report 2017;130.

35. Messias DKH. Transnational health resources, practices, and perspectives: Brazilian immigrant women's narratives. J Immigr Health. 2002;4:183-200.

36. Cadge W, Ecklund EH. Religious service attendance among immigrants: evidence from the new immigrant survey-pilot. Am Behav Sci. 2006;49:1574-95.

37. Austin SA, Claiborne N. Faith wellness collaboration: a community-based approach to address type II diabetes disparities in an African-American community. Soc Work Health Care. 2011;50:360-75.

38. Hou S-I, Cao X. A systematic review of promising strategies of faith-based cancer education and lifestyle interventions among racial/ethnic minority groups. J Cancer Educ. 2018;33:1161-75.

39. Maynard MJ. Faith-based institutions as venues for obesity prevention. Curr Obes Rep. 2017;6:148-54.

40. Birt L, Scott S, Cavers D, Campbell C, Walter F. Member checking: a tool to enhance trustworthiness or merely a nod to validation? Qual Health Res SAGE Publications Inc. 2016;26:1802-11.

41. Gonçalves M, Cook B, Mulvaney-Day N, Alegría M, Kinrys G. Retention in mental health care of Portuguese-speaking patients. Transcult Psychiatry. 2013;50:92-107.

42. Lie DA, Lee-Rey E, Gomez A, Bereknyei S, Braddock CH. Does cultural competency training of health professionals improve patient outcomes? A systematic review and proposed algorithm for future research. J Gen Intern Med. 2011;26:317-25.

43. Sundstrup E, Seeberg KGV, Bengtsen E, Andersen LL. A systematic review of workplace interventions to rehabilitate musculoskeletal disorders among employees with physical demanding work. J Occup Rehabil [Internet]. 2020. Available from: https://doi.org/10. 1007/s10926-020-09879-x. Accessed 21 May 2020. 
44. Van Eerd D, Munhall C, Irvin E, Rempel D, Brewer S, van der Beek $\mathrm{AJ}$, et al. Effectiveness of workplace interventions in the prevention of upper extremity musculoskeletal disorders and symptoms: an update of the evidence. Occup Environ Med. 2016;73:62-70.

45. Gute DM, Siqueira E, Goldberg JS, Galvão H, Chianelli M, Pirie A. The Vida Verde Women's Co-Op: Brazilian immigrants organizing to promote environmental and social justice. Am J Public Health. 2009;99:S495-8.

46. Alvarez CP, Davidson PM, Fleming C, Glass NE. Elements of effective interventions for addressing intimate partner violence in Latina women: a systematic review. PLoS ONE [Internet]. 2016;11. Available from: https://www.ncbi.nlm.nih.gov/pmc/ articles/PMC4978383. Accessed 4 Mar 2020.

47. Cantor C, Crystal-Mansour D, Dipko S. Health Information National Trends Survey (HINTS) 2007 Final Report. Final Rep. 2007:103.
48. Fishbein M, Ajzen I, Ajzen I. Predicting and changing behavior: the reasoned action approach [Internet]. Psychology Press; 2011. Available from: https://www.taylorfrancis.com/books/ 9780203838020. Accessed 21 May 2020.

49. McNeill LH, Coeling M, Puleo E, Suarez EG, Bennett GG, Emmons KM. Colorectal cancer prevention for low-income, sociodemographically-diverse adults in public housing: baseline findings of a randomized controlled trial. BMC Public Health. 2009;9:353.

Publisher's Note Springer Nature remains neutral with regard to jurisdictional claims in published maps and institutional affiliations. 